Международный форум «Peer Review Week 2020», 21-25 сентября 2020 г.:

Сессия Российского отделения Европейской ассоциации научных редакторов (EASE) и Ассоциации научных редакторов и издателей (АНРИ), 24 сентября 2020 г., Москва, Россия

\title{
Peer Review Week 2020, September 21-25, 2020: Joint Session of the Russian Regional Chapter of EASE \& Association of Science Editors and Publishers (ASEP), September 24, 2020, Moscow, Russia
}

\begin{abstract}
«Peer Review Week» («Неделя рецензирования», https://peerreviewweek.wordpress.com/) представляет собой ежегодное глобальное мероприятие, посвященное роли рецензирования и рецензентов в поддержании качества научной коммуникации в широком ее смысле. В контексте недели рецензирования эксперты, учреждения и организации обсуждают и анализируют параметры качественной экспертной оценки, ее эффективные формы и принципы ее реализации. В 2020 г. неделя рецензирования прошла с 21 по 25 сентября, а ее тема «Доверие к рецензированию», была сфокусирована на «механике» реализации процесса экспертной оценки и ее влиянии на усиление доверия читателей и общества не только к журналам, исследователям и их исследованиям, но и к деятельности правительств. Как совершенно обоснованно отмечает директор по взаимодействию с сообществами NISO (The National Information Standards Organization, https:// www.niso.org/) и член учредительного комитета недели рецензирования A. Meadows, тема доверия к научным исследованиям и деятельности рецензентов особенно актуальна для современного этапа развития общества. В течение длительного времени политики-популисты осуждали ценности рецензирования, отказывались выделять финансы на проведение исследований, зачастую отрицали значимость их результатов. COVID-19 стал переломным моментом, изменившим отно-
\end{abstract}

шение и общества, и правительств к рецензированию и роли исследователя в жизни общества [1].

В качестве целей «Peer Review Week 2020» были провозглашены:

1) обоснование центральной роли рецензирования в научной коммуникации;

2) демонстрация значимости деятельности научных редакторов и рецензентов;

3) ознакомление с результатами исследований по проблематике рецензирования и продвижение передового опыта его реализации;

4) демонстрация инноваций в области рецензирования и практик их внедрения.

Мероприятия недели рецензирования варьировались от неформальных встреч до модерируемых панелей, публикаций видеороликов на тему, сообщений в блогах, публикации инфографики, организации кампаний в различных медиа и др.

Сопредседатель Руководящего комитета «Peer Review Week 2020» Ph. Hurst, представляющий Королевское общество (The Royal Society), отметил, что для общества, его правительственных структур и ученых жизненно важно осознавать, что исследования и данные, на которые они полагаются, были оценены и протестированы [2]. Второй сопредседатель Руководящего комитета «Peer Review Week 2020» Lou Peck акцентировал статус мероприятия как открытой платформы, позволяющей озвучить то, что для общества означает доверие к рецензированию [2]. 
В формате «Peer Review Week 2020» наиболее широкое обсуждение получили следующие проблемы.

Качественное рецензирование с точки зрения его содержания и личности автора. Так, менеджер по рецензированию J. Wallace (The American Society for Microbiology) в своем блоге выделила базовые требования к качественному рецензированию и статусу качественного рецензента: соблюдение дедлайнов и своевременное уведомление редакторов о форс-мажорах; целенаправленность действий даже в ситуации, когда рецензирование занимает большее количество времени, нежели предполагал рецензент; стремление дать значимые для автора комментарии даже в ситуации понимания, что рукопись в текущем ее виде непригодна к публикации; оценивание рукописи по таким аспектам, как оригинальность, уместность в контексте предметного поля журнала и актуальность (форматирование рукописи и ее лингвистическое оформление вторичны - языковые барьеры авторы устранят в случае потенциальной возможности принятия рукописи к печати); ознакомление с рекомендациями журнала для рецензентов и описанием его предметного поля и миссии; стремление к научению и развитию представителей научного сообщества: автор должен понимать причины отклонения и принятия рукописи; рецензии, которые он читает, помогают ему стать хорошим рецензентом (следовательно, очень важно, чтобы рецензия была конкретной, а не абстрактной, и четко описывала сильные и слабые стороны рукописи); способность обоснованно отказаться от рецензирования, если рецензент перегружен, чтобы не затягивать процесс рецензирования; рекомендация своих коллег в качестве рецензентов в ситуации, когда рецензент в силу обстоятельств не может принять статью на рецензирование; способность быть смелым и конструктивным в своих рекомендациях автору; умение составлять отзывы на рукописи так, чтобы не оскорбить автора (вне догматических и грубых заявлений) [3].

Особую значимость приобретает необходимость получения знаний в области проведения рецензирования как для молодых ученых, так и для ученых, не занимавшихся рецензированием ранее. Эти знания нужны не только для организации самого процесса рецензирования, но и для осознания всеми членами научного сообщества определяющей значимости экспертизы исследований равных равными (peer review) для создания пространства подлинно научной ком- муникации и отражения социальной значимости научных исследований.

Эпидемия коронавируса породила ситуацию, в рамках которой возникла острая необходимость в максимально оперативной публикации исследований, посвященных коронавирусу, борьбе с ним и преодолению его влияния на все сферы жизнедеятельности общества. Шквал статей в рамках указанной проблематики обусловил необходимость специалистам в области рецензировать десятки статей в неделю. Безусловно, они не могли долго работать в таком режиме, и редакциям пришлось обращаться к исследователям, которые ранее либо не занимались рецензированием, либо не обладали опытом реализации эффективной экспертной оценки рукописей. Как результат, со всей очевидностью проявилась проблема неготовности значимой части научного сообщества реализовывать прозрачное и этичное рецензирование.

Контекст современных реалий продемонстрировал и значимость института препринтов как еще одного инструмента процесса рецензирования. Препринты позволяют максимально оперативно и открыто опубликовать результаты проведенного исследования и практически в режиме реального времени получить комментарии представителей научного сообщества. Вместе с тем они же позволяют максимально оперативно распространять и фальсифицированную и подтасованную информацию. Неслучайно многие площадки, размещающие препринты, подчеркивают предварительный характер результатов, представленных в препринтах.

Дихотомия коронавирусного контекста, как отмечает главный редактор The New England Journal of Medicine E. Rubin, продемонстрировала еще одно противоречие. В период, когда врачи борются с кризисом, быстродоступная информация самого разного качества важнее, нежели точная информация, к которой нельзя оперативно получить доступ [4]. Последняя может просто обесцениться с течением времени.

Международная ассоциация научных, технических и медицинских издателей (The International Association of Scientific, Technical and Medical Publishers) пришла к пониманию необходимости стандартизации определений и терминологии в сфере открытого рецензирования. Результатом этого решения стал проект по созданию таксономии рецензирования. Проектная группа в составе C. Black, M. Kowalczuk, S. Alam, E. Moylan, L. Jones, В. Mehmani, G. Stein, A. Larkin A. и J. van Rossum реализовывала работу над таксономией, исходя из ее способности (1) помочь редакциям научных 
журналов сделать процесс рецензирования статей и журналов более прозрачным; (2) позволить обществу, читателям оценивать и сравнивать методы рецензирования в разных журналах. Рабочая группа не просто разработала стандартизированные определения в рамках таксономии, но и сформулировала рекомендации по их внедрению.

Таксономия описывает различные модели рецензирования, связанные с четырымя этапами процесса рецензирования:

1) открытость информации о личности участника процесса рецензирования;

2) с кем взаимодействует рецензент;

3) какая информация о процессе рецензирования публикуется;

4) реализуется ли постпубликационное комментирование, рецензирование [5].

Таксономия получила широкое обсуждение в среде научных редакторов и проходит этап валидации.

Открытость информации о личности участника процесса рецензирования (описывает степень, до которой личности участников процесса рецензирования замаскированы или открыты. Анонимность личных данных может быть раскрыта по окончании процесса рецензирования всем участникам этого процесса после принятия рукописи к публикации или опубликована на странице статьи в печатной / онлайн-версии журнала):

1) все идентичности открыты (авторы обладают информацией о личности рецензентов, рецензенты обладают информацией о личности автора(ов), информация об авторе (-ах) и рецензентах доступна редактору, в том числе и принимающему окончательное решение);

2) односторонняя анонимность (авторы не обладают информацией о личности рецензента, рецензенты обладают информацией о личности автора, информация об авторах и рецензентах доступна редактору, в том числе и принимающему окончательное решение);

3) двусторонняя анонимность (авторы не обладают информацией о личности рецензента, рецензенты не обладают информацией о личности автора, информация об авторах и рецензентах доступна редактору, в том числе и принимающему окончательное решение);

4) трехсторонняя анонимность (авторы не обладают информацией о личности рецензента, рецензенты не обладают информацией о личности автора, информация об авторах и рецензентах недоступна редактору, в том числе и принимающему окончательное решение).
Рецензенты взаимодействуют (описывает прямое взаимодействие, или обмен информацией (через электронную редакцию журнала или электронную почту) в течение процесса рецензирования. Могут быть реализованы несколько типов подобного взаимодействия, если это необходимо. Какая бы коммуникация о процессе рецензирования ни реализовывалась после публикации рукописи, она подпадает под категорию «Опубликованная информация о процессе рецензирования»):

1) с редактором - коммуникация между редактором и рецензентом (традиционная модель, известная также как «независимое рецензирование». Личности участников процесса рецензирования могут быть открыты или закрыты);

2) с другими рецензентами - прямое взаимодействие / сотрудничество (через электронную редакцию журнала или электронную почту) между рецензентами, или возможность ознакомиться с рецензиями всех рецензентов и прокомментировать их перед окончательным представлением рецензентами своих рецензий редактору. Личности участников процесса рецензирования могут быть открыты или закрыты;

3) с авторами - прямое взаимодействие / сотрудничество (через электронную редакцию журнала или электронную почту) между автором и рецензентами перед окончательным представлением рецензентами своих рецензий редактору. Личности участников процесса рецензирования могут быть открыты или закрыты.

Опубликованная информация о процессе рецензирования (относится $к$ информации о процессе рецензирования, представленной вместе с опубликованной статьей рукописи на странице статьи на ее странице. Из предложенных ниже опциий нужно выбрать только те, которые применимы к политике журнала):

1) информация отсутствует (информация о процессе рецензирования или принятии редактором окончательного решения не размещается);

2) краткое изложение рецензии (могут быть представлены выдержки из рецензии или ее краткое изложение, или описан процесс рецензирования);

3) отчеты рецензентов (публикуется отчет рецензента целиком);

4) отчеты рецензентов с согласия авторов (публикуется отчет рецензента целиком, если корреспондирующий автор не против);

5) отчеты рецензентов с согласия рецензентов (публикуется отчет рецензента целиком, если рецензент не против);

6) рукопись в первоначальном варианте; 
7) рукопись в первоначальном варианте с согласия авторов;

8) переписка авторов / рецензентов (включая письмо редактора с окончательным решением о принятии статьи и ответы рецензентов (контраргументы));

9) информация о личностях рецензентов;

10) информация о личностях рецензентов с согласия рецензентов;

11) информация о личностях редакторов (выпускающих редакторов).

Постпубликационное комментирование / рецензирование представляет собой комментирование / рецензирование опубликованной статьи (печатной или онлайн-версии). Такие типы статей, как комментарий / ответ / письмо, не подвергаются постпубликационным комментариям после опубликования, поскольку они являются самостоятельным типом публикации, не подлежащим рецензированию. Этот тип рецензирования используется только тогда, когда это применимо (когда политика журнала предполагает такой тип рецензирования):

1) открытое - комментирование доступно каждому. Комментирование может быть реализовано как анонимное, только для авторизованных пользователей и/или зарегистрированных пользователей (например, вход с использованием личного ORCID рецензента);

2) по приглашению - только редактор (или издатель) подбирает и/или приглашает специалистов, которые могут прокомментировать уже опубликованную статью [5].

Широкое обсуждение получил и вопрос прозрачности рецензирования и путей избегания предвзятости рецензентов. Эта тема, заявленная на «Peer Review Week 2017», безусловно, остается одним из ключевых компонентов доверия как к рецензированию, так и к институту научного исследования. Доверие выступает в качестве краеугольного камня научной коммуникации и рецензирования как эффективного инструмента обеспечения ее прозрачности. Особенности современной коммуникации породили мощные инструменты дезинформации, включая платформы социальных сетей и политизированные СМИ. Антинаучные движения, будь то противники вакцинации или ношения масок, так же являются маркерами истории недоверия [6].

В контексте научной коммуникации крайне важно повышать доверие ко всем ее авторам: исследователям, рецензентам, редакциям научных журналов и их контенту и т. д. Для любого исследования и распространения его результатов критически важно, чтобы ему доверяли читатели. Иными словами, чтобы они были уверены в том, что само исследование было проведено объективно и его результаты не сфальсифицированы, а рецензенты, которые проводили его экспертизу, являются признанными специалистами в области и проводят оценку строго в соответствии с нормами и этикой рецензирования. И именно редакция журнала призвана тщательно отслеживать этичность деятельности рецензентов.

Качество рецензирования, разнообразие форм его реализации (слепое, открытое, метарецензирование, пострецензирование и др.), следование нормам этики рецензирования имеют сегодня первостепенное значение. Отсюда очевидно, что обеспечение понимания обществом сути исследовательского процесса и центральной роли, которую в нем играет экспертная оценка, имеет решающее значение для повышения общественного доверия к результатам исследований. Вне доверия продвижение знания невозможно.

«Peer Review Week 2020» акцентировала не только экспертную оценку журнальной статьи. Речь идет об экспертной оценке во всей исследовательской экосистеме: от процесса подачи заявки в аспирантуру до защиты диссертации; от подачи заявки на грант до представления результатов его реализации; от сбора данных исследования до рецензирования рукописи по его результатам. При этом важно понимание, что даже самое качественное рецензирование не способно гарантировать безошибочность результатов исследований, но оно сводит этот риск к минимуму.

Экспертная оценка, будучи аддитивной по своей сути, выступает в качестве неотъемлемой части процесса перманентного выстраивания эффективной и прозрачной экосистемы научной коммуникации. Рецензирование позволяет выстроить канал постоянной обратной связи и выступает инструментом валидации знания. Как результат, исследователи могут опираться на достижения своих предшественников, а политики - принимать на основании новейших научных исследований взвешенные и общественно значимые исследования. Для того чтобы эти политические решения были эффективными, широкая общественность также должна доверять исследованиям, на которых они основаны [6]. Рецензирование призвано преобразовывать исследования в надежные и заслуживающие доверия фундаментальные знания.

Значимость «Peer Review Week» и ее востребованность нашли отражение в ее широком анонсировании в пространстве научной коммуника- 
ции: Wiley, Crossref, журнал Nature, Asian Council of Science Editors (ACSE), Enago Academy, Editage Insigts и др. Ряд журналов посвятили этому событию сообщения в блогах и редакторские статьи. Так, редакция журнала Communications Biology, вслед за анонсом темы «Peer Review Week 2020», связалась с 40 рецензентами, которые оказывали наибольшее влияние на процесс продвижения рукописей, чтобы узнать, что они думают о доверии к рецензированию. «Peer Review Week», отмечает редактор журнала L. Grinham, представляет и возможность проанализировать и гендерно-возрастной состав рецензентов журнал, что позволит избежать гендерного и возрастного неравенства. Подобные практики призваны укрепить доверие к редакционной команде журнала [7]

Характерной особенностью «Peer Review Week 2020» стал рост глобального участия. Так, Китайская академия наук, отделения Европейской ассоциации научных редакторов целого ряда стран (в том числе и российское) впервые были представлены в числе участников.

24 сентября 2020 г. состоялась сессия российских членов Европейской ассоциации научных редакторов (EASE) и Ассоциации научных редакторов и издателей (АНРИ) в рамках «Peer Review Week 2020». В мероприятии приняли участие более 100 участников. В своем приветственном слове руководитель Российского отделения EASE, член АНРИ Елена Викторовна Тихонова отметила важность экспертной оценки в системе глобальной научной коммуникации, подчеркнув, что темой «Peer Review Week 2020» выступает проблематика доверия к институту рецензирования на всех его уровнях (от уровня научной рукописи до экспертизы заявки на грант и т. д.).

Д-р Simon Kerridge, руководитель отдела исследовательской политики и поддержки Университета Кента, рассказал о типологии видов и типов ролей участников исследования в системе CREdiT (Contributor Roles Taxonomy). Данная система описывает 14 ролей, соответствующих вкладу каждого из соавторов в проведение и описание исследования, в прозрачном, последовательном и структурированном формате. Авторские роли могут быть связаны со следующими аспектами исследования:

1) концептуализация идеи (conceptualization) формулировка и развитие исследовательских целей и задач;

2) курирование данных (data curation) - создание метаданных, упорядочивание данных исследования (включая подбор программного обеспечения, если оно необходимо для интерпретации данных) как для их первоначального использования, так и для последующего повторного использования;

3) анализ данных (formal analysis) - применение статистических, математических, вычислительных или других формальных методов для анализа или синтеза данных исследования;

4) финансирование (funding acquisition) - получение финансовой поддержки для проекта, ведущего к данной публикации;

5) проведение исследования (investigation) проведение экспериментов или сбор данных;

6) описание методологии (methodology) - проектирование и разработка методологии исследования, создание моделей;

7) администрирование проекта (project administration) - ответственность за управление исследовательским проектом и координацию реализации исследовательской деятельности;

8) ресурсы (resources) - предоставление, обеспечение доступа к исследовательским материалам, реагентам, пациентам, лабораторным образцам, инструментам, компьютерным ресурсам или другим инструментам анализа;

9) программное обеспечение (software) программирование, разработка программного обеспечения, проектирование компьютерных программ, создание компьютерного кода и поддерживающих алгоритмов, тестирование существующего компонента кода;

10) научное руководство (supervision) - ответственность за планирование этапов выполнения исследовательской деятельности, включая наставничество;

11) валидация (validation) воспроизводимости и статистической значимости результатов / экспериментов и других результатов исследований;

12) визуализация (visualization) - подготовка, создание рукописи, в частности визуализация / представление данных;

13) написание рукописи - создание первоначального варианта рукописи (writing - original draft, подготовка, создание и/или презентация рукописи (включая перевод));

14) написание - просмотр и редактирование рукописи (writing - review \& editing, работа по доработке рукописи по результатам рецензирования, комментариев, включая все предпубликационные этапы продвижения рукописи и ее пострецензирование) [8].

Таксономия ролей участников исследования и их вклада в подготовку публикаций удобна для понимания, применения и позволяет минимизировать ее некорректное использование. Она дает 
возможность рецензентам, в случае открытого рецензирования, получить представление о характере взаимодействия авторов. Спикер затронул основные проблемы, которые возникают при рецензировании, и подчеркнул, что правильное распределение ролей соавторов в соответствии с представленной им типологией поможет понять вклад каждого из них в конечный итог исследования - научную статью.

Последовавший вопрос о том, должен ли рецензент учитывать роль авторов при открытом рецензировании и насколько это корректно, породил дискуссию о том, что в России институт авторства остается пока размытым. В процессе дискуссии было отмечено, что определение ролей авторов является очень актуальным для редакторов журналов и рецензентов как с точки зрения публикационной этики, так и с точки зрения взаимодействия авторов в ходе предпубликационной подготовки рукописи. S. Kerridge подчеркнул, что маркерами авторства выступают: значимый вклад в написание статьи, обсуждение и финальная вычитка статьи и согласие принять ответственность за ее содержание. Вместе с тем, некоторые из выделяемых ролей (финансирование, перевод, предоставление материалов) оспаривались некоторыми участниками сессии как нерелевантные для автора. Было предложено включать благодарность подобным участникам процесса создания рукописи в случае, если они выполняли исключительно три указанные роли и не совмещали их с другими ролями, указанными в таксономии).

Ольга Владимировна Кириллова, президент Ассоциации научных редакторов и издателей (АНРИ), главный редактор журнала «Научный редактор и издатель», председатель Scopus ECSAC-RF, свое выступление посвятила теме «На чем учиться и учить рецензированию?». Осветив вопросы терминологии, она развела понятия «peer review», смысл которого заключается в оценке рукописи компетентными коллегами, и «book review», обзор книги, которые зачастую некорректно маркируют термином «review». Последний же применим к «обзору» как типу публикации. О. В. Кириллова указала на необходимость при написании этих терминов не отделять термин «review» от слов «peer» или «book», в зависимости от контекста. Хотя история рецензирования началась в 50-е гг. XX в., рост интереса к нему пришелся на начало 70-х гг., сейчас этот вопрос как никогда актуален. Особенно остро в настоящее время, по мнению спикера, не хватает специальной литературы по рецензированию - справочников, методических пособий, как переводных, так и отечественных. Именно качественные книги, статьи с примерами могут послужить значимой базой для обучения рецензированию. Далее спикер перешла к возможностям постпубликационного рецензирования и отметила, что в настоящее время технически возможно выполнять рецензирование не только перед изданием рукописи, но и после ее опубликования. Такой вид рецензирования, по ее мнению, позволяет инициировать более глубокое и прозрачное научное обсуждение содержания статьи. Она отметила, что прозрачность - это основа для совершенствования исследований, в журнале и на сайте журнала должна ясно прослеживаться работа над статьей после замечаний рецензента. Далее спикером были прокомментированы перспективы создания коллективной системы независимого рецензирования российских научных журналов.

Елена Викторовна Тихонова, руководитель Российского отделения EASE, член АНРИ, зав. редакцией, основатель и заместитель главного редактора журнала Journal of Language and Education, рассказала о новых формах рецензирования: метарецензировании и пострецензировании. Она отметила, что данные виды рецензирования призваны усилить доверие к институту рецензирования, а и их появление обусловлено возникшей критикой двойного слепого рецензирования. Качественное рецензирование - залог успешной научной коммуникации, что требует высокого уровня подготовленности к реализации рецензирования. К сожалению, далеко не все рецензенты способны честно оценить свою компетентность и признаться в неспособности дать взвешенную оценку исследования, боясь имиджевых потерь. Зачастую «занятые» рецензенты делегируют свои обязанности менее квалифицированным коллегам или аспирантам и не контролируют результат, кроме того, иногда согласие дать рецензию используется для собственного продвижения, при этом качество рецензии волнует такого рецензента меньше всего.

Именно в таких случаях на выручку приходит метарецензирование. Метарецензия призвана обобщать комментарии всех рецензентов на рукопись, объективно суммируя ее слабые и сильные стороны, пояснять, почему те или иные комментарии считаются более весомыми, и подразумевает анализ всех рецензий на рукопись. Именно метарецензент в спорном случае принимает окончательное решение о возможности рекомендации рукописи к публикации, подкрепляя его обоснованным взвешенным мнением. 
Е. В. Тихонова затронула и проблематику открытого рецензирования с позиций прокламируемой рядом журналов возможности пострецензирования статей, представленных в контексте открытого рецензирования и возможности опубликования версий этой статьи. Инструмент пострецензирования, по мнению спикера, порождает ряд вопросов этического плана: должно ли оно быть открытым или слепым? Как должен вести себя автор, если рецензия на его статью поступила через достаточно большой промежуток времени, может ли он вносить в уже опубликованную статью обновленные данные и опираться на литературу, которая появилась после опубликования статьи? Как будет присваиваться doi второй версии статьи? Ответы на эти вопросы все еще обсуждаются научным сообществом.

За выступлением последовало обсуждение вопросов, связанных с ролью редактора и метарецензентов, роли главного редактора и редколлегии в принятии решения после комментариев метарецензента, а также статус статьи после пострецензирования - будет ли она считаться дублированием публикации и не потеряет ли она при этом свою оригинальность. Большое количество заданных вопросов еще раз подчеркнуло необходимость дальнейшего изучения данной темы и ее актуальность.

Выступление Анны Викторовны Кулешовой, директора Департамента издательских проектов ВЦИОМ, ответственного редактора журнала «Мониторинг общественного мнения: экономические и социальные перемены» (ВЦИОМ) и председателя Совета по этике научных публикаций АНРИ, традиционно было посвящено вопросам публикационной этики. Анна Викторовна осветила тему экологии рецензирования. Отметив, что в настоящее время университет потерял свою былую элитарность, а громкое имя может не означать ровным счетом ничего, спикер указала на необходимость для редакторов проверять, являются ли организации, о которых сообщают авторы в своих рукописях, реальными, действительно ли авторы являются их сотрудниками. Кроме этого, редакторы должны оперативно общаться с авторами, не задерживая ответ месяцами, а также важно согласовывать текст со всеми авторами до публикации, это снизит риск ретракции в случае, если кто-то из авторов не знал о том, что текст принят к публикации.

А. В. Кулешова обратила внимание на тот факт, что понятие рецензирования как поиска истины сегодня претерпевает деформацию. Рецензирование зачастую воспринимается как проявление лояльности, как помеха относительно ключевых обязанностей или как пространство для самоутверждения. Патологией рецензирования считается подтасовка фактов, сокрытие собственных данных при использовании чужих и нарушение главного правила науки - обязательного указания использованных в работе трудов других ученых.

Следует помнить о том, что рецензия - это ножницы, которыми легко пораниться, поэтому важно учитывать, что эксперты также могут ошибаться. В данном случае на первый план выходит роль редактора, который должен уметь отфильтровывать рекомендации рецензентов, смягчив их тон (в случае необходимости), и который не будет перегружать рецензента работой с рукописями, не соответствующими требованиям к качеству контента.

Отметив важность проверки на антиплагиат, Анна Викторовна затронула вопрос раскрытия имен рецензентов после публикации. По мнению спикера, смысл двойного слепого рецензирования заключается в том, чтобы уменьшить предвзятость в ходе подготовки экспертного заключения. Анонимность авторов заканчивается после публикации, но анонимность рецензентов остается незыблемой. Разумным, по ее мнению, представляется решение раскрыть информацию о рецензенте после публикации, если нет возражений с его стороны.

В настоящее время важно повысить конструктивность и снизить недооцененность рецензирования именно через экологичное рецензирование, которое позволило бы ученым получать оценку в долгосрочной перспективе, снизило бы конфликт интересов между авторами и рецензентами. Кроме того, частично открытая информация о рецензировании и финансовое поощрение вузами проводимых их сотрудниками экспертиз рукописей для журналов могли бы повысить эффективность и востребованность института рецензирования.

Под экологичной рецензией следует понимать ту рецензию, прочитав которую, редактор и автор понимают, что делать дальше, как нужно работать с текстом, подобная рецензия должна вдохновлять на работу, быть беспристрастной, конструктивной, оцененной должным образом.

Анна Викторовна рассказала также о рекомендациях Совета по этике АНРИ, согласно которым стоит забыть про субординацию и особые правила для уважаемых людей, нельзя соучаствовать в нарушениях норм, особенно это касается приписного авторства, не следует выводить каждое нарушение норм в плоскость служебных разбирательств, а также ретрагировать статьи в любой 
непонятной ситуации. СОРЕ и Совет по этике АНРИ рекомендуют для редакторов установить процедуру, при которой рецензенты, которые внесли свой вклад в успешную публикацию, будут получать признание (будь то официальная справка или просто упоминание имени рецензента на веб-сайте). Подобное упоминание может помочь в стимулировании экспертов. Кроме того, редакторы должны продумать пути сокращении времени на рецензирование рукописей. Поскольку многие рецензенты превышают установленные сроки, возможно, сокращение сроков приведет к ускорению рецензионного цикла.

Спикер отметила, что вместо таблиц для рецензирования журналам следует предлагать рецензентам четкие указания и критерии оценивания рукописи (например, ясность, актуальность, релевантность и полнота). Давать варианты вопросов, ответы на которые помогут рецензентам сформировать корректное мнение о рукописи, а редакторам - принять решение о публикации. В заключении Анна Викторовна обратила внимание на то, что основой научной коммуникации должна оставаться порядочность.

Arend Kuester, директор по связям со спонсорами в Springer Nature, рассказал о том, как строится процесс публикации в открытом доступе. Лейтмотивом его выступления стала мысль о том, что доверие имеет первостепенное значение. Он начал свой доклад с описания миссии Springer Nature, которая заключается в продвижении знания и создании условий для его востребованности в обществе. Следовательно, все должны иметь доступ к знаниям и доверять им. И роль рецензента в этой связи получает определяющее значение. Под открытым доступом следует понимать бесплатный, мгновенный онлайн-доступ к исследовательским статьям без ограничений, а также право совместного пользования этими статьями в цифровом пространстве. Спикер рассказал о том, что в 2010 г., еще до начала его карьеры в Springer Nature, у издателей, с которыми он сотрудничал, не было электронной редакции для подачи рукописей, специализированных платформ, практически отсутствовал штат сотрудников, не было редакционных коллегий, но была мотивация и возможность нанять хороших сотрудников, а также была бизнес-модель, которая успешно развивалась. В то же время им приходилось решать, как им развиваться и расти при огромном количестве хищнических журналов, как сделать так, чтобы исследователи могли доверить им свои исследования. Тогда он и начал заниматься вопросом доверия и выделил элементы доверия:

1) бренд и репутация издателя;
2) ссылки, цитирование, сети;

3) активное сообщество;

4) процесс обработки рукописи, включая рецензирование и политику журнала;

5) доверие к открытому доступу (четкое осознание, что качество журнала и процесс рецензирования в открытом доступе не отличается от качества журналов по подписке, а количество цитирований и скачиваний наоборот увеличивается);

6) внедрение инноваций в издательский процесс;

7) умение принимать непростые решения относительно вопросов этики и безукоризненная репутация;

8) люди, работающие в издательстве.

A. Kuester отметил необходимость помнить, что статья в процессе подготовки изменяется и трансформируется, а каждая отклоненная статья перед отклонением рецензируется специалистами и обрабатывается сотрудниками редакции, и, соответственно, все затраты должны быть оправданны и компенсированы. Поэтому важным он считает глобальный диалог открытой науки (The Open Science Conversation), который строится на взаимодействии доверия, использовании достоверных данных, факторах воздействия и метриках общественной науки и понимании, что редакциям нужно осуществлять финансирование собственной деятельности.

Спикер также акцентировал необходимость для каждого ученого регистрации собственного ORCID, который служит важнейшим инструментом его идентификации в мировом научном сообществе.

Свое выступление А. Kuester закончил, озвучив направления деятельности Springer Nature по развитию открытого доступа, доверия к научным исследованиям и рецензированию.

Павел Геннадьевич Арефьев, руководитель аналитического отдела Научной электронной библиотеки, рассказал о перспективах размещения рецензий на публикации на платформе eLibrary.ru в открытом доступе и сопутствующих проблемах. Он отметил, что рецензирование - это важнейший процесс в производстве научного знания, без рецензии не может быть публикации, но и открытая, и закрытая системы рецензирования вызывают очень много споров. Далее он перешел к вопросу социологии научного рецензирования и отметил, что в академическом сообществе существуют два уровня рецензирования научных результатов и два кластера рецензентов. Первые это избранные эксперты, которые посредством 
рецензирования оценивают рукописи научных работ до момента издания, публикации. И вторая группа - это читатели, которые оценивают прошедшие рецензирование и уже опубликованные работы в собственных трудах через цитирование или же через пострецензирование в онлайн- или оффлайн-формате.

Также Павел Геннадьевич обратил внимание на то, что система рецензирования воплощает все нормы научного этоса, сформулированные Р. Мертоном: универсализм, коллективизм, бескорыстность, организованный скептицизм.

После этого докладчик рассказал об истории отношения РИНЦ к рецензированию и отметил, что с 2010 г. в интерфейсе РИНЦ есть возможность для читателей оставлять комментарии и пострецензии на опубликованные произведения, размещенные на платформе eLibrary.ru. C 2018 г. все периодические издания, которые стремятся попасть в РИНЦ, обязаны предоставить в Экспертный Совет РИНЦ рецензии на произведения, опубликованные в изданиях-заявителях. С 2019 г. в РИНЦ реализован механизм публикации рецензий на рукописи научных произведений.

Далее в сообщении был приведен пример открытой рецензии в РИНЦ, которая, по сути, имитирует рецензию и никоим образом не способствует росту уровня доверия к научным исследованиям и их рецензированию. В конце своего выступления спикер выразил мнение, что РИНЦ - это зеркало российской системы научной коммуникации, а рецензии, которые размещены в РИНЦ, могут свидетельствовать о наличии проблем и болезней в этой системе, причем болезней хронических.

Любомир Димитров Пенев, директор издательства Pensoft, рассказал о новых способах рецензирования и оценки нагрузки и качества рецензентов на издательской платформе полного цикла на основе XML ARPHA (authoring, reviewing, publishing, hosting, archiving). Он отметил, что в 2020 г. ARPHA предлагает функции оценки нагрузки и качества рецензирования, новые статистические показатели состояния журнала, автоматические отчеты главному редактору по статистикам развития и продвижения журнала, модуль для препринтов по выбору журнала и авторов, систему управления спецвыпусков и тематических коллекций, новую форму заявки на позицию редактора, всплывающие напоминания об актуализации экспертизы, новые тарифные планы и скидки. Также спикер привел сравнительную статистику по срокам от подачи до принятия статьи в 2019 и 2020 гг., которая наглядно продемонстрировала сокращение сроков обра- ботки статьи в 2020 г. Значимым преимуществом данной платформы можно считать возможность учета загрузки рецензентов. 9 российских журналов уже используют данную платформу, часть из них индексируется в Scopus.

Татьяна Анатольевна Скрыпник, технический редактор НП «Вопросы экономики» и Russian Journal of Economics, дала краткий комментарий по работе с данной системой.

Владимир Владимирович Лебедев, IT-директор платформы Elpub, рассказал об аналитических инструментах в редакционном процессе. По его мнению, доверять можно только объективной аналитике, полученной с помощью алгоритмов на основе данных журнала. Elpub предлагает издателям сервис тематического и авторского анализа журналов и помогает издателю ответить на вопросы: какой журнал вы издаете? в каком состоянии ваш журнал сейчас? куда стоит двигаться дальше для достижения ваших целей? Для этого сервис позволяет: использовать аннотации и полные тексты для анализа; создавать тематический профиль журнала; проводить сравнение тематического профиля с профилями ведущих мировых журналов в той же научной области. Далее эксперты интерпретируют результаты анализа и готовят текстовый отчет.

Олеся Анатольевна Парпара, ответственный редактор журнала «Альманах клинической медицины», поделилась пятилетним опытом размещения журнала на платформе Elpub, рассказав о технических сложностях кастомизации Open Journal System (OJS), предложила улучшения и объяснила, почему рецензенты неохотно пользуются этой системой. Зачастую они испытывают затруднения при работе в электронной редакции, в том числе по причине неинтуитивного интерфейса, что актуализирует необходимость технической подготовки рецензентов. Цифровая компетенция рецензента тоже требует внимания редактора.

Денис Юрьевич Большаков, заместитель главного редактора журнала «Вестник Концерна ВКО “Алмаз - Антей”», поделился опытом привлечения молодых ученых в качестве рецензентов в научно-технический журнал. Он объяснил, что целью такого эксперимента было сокращение времени рассмотрения статей. Он привел статистику, которая подтвердила, что молодые ученые справляются с задачей не хуже зрелых рецензентов. Вместе с тем спикер указал на необходимость учета в подобной практике области научного знания. В сфере информационных технологий, например, молодые исследователи зачастую оказываются в преимущественной ситуации, поскольку 
более гибко откликаются на все инновации и владеют их спецификой в большей степени.

Юрий Иванович Филиппов, руководитель подразделения ООО «Эко-вектор» в г. Москва, член АНРИ, руководитель редакционно-издательского отдела ФГБУ «НМИЦ эндокринологии» Минздрава России, член редколлегии журнала «Сахарный диабет», рассказал о прикладных моделях рецензирования в научных журналах на базе OJS и их использовании в реальной практике работы редакций. Им был продемонстрированы примеры рецензирования в журналах медико-биологического профиля «Экологическая генетика» и Acta Naturae. Он отметил, что электронная система рецензирования очень удобна. Переход на открытую электронную платформу занимает у разных журналов от двух недель до полугода.

Спикер указал, что работа редакции с рецензентами и авторами при помощи почтового ящика в ситуации отсутствия электронной рукописи в меньшей степени защищает рукопись, потому что письмо могут переслать и передать другим людям. Рецензию также может написать другой человек, и редакция точно не будет знать, кто же на самом деле выполнил рецензирование. С другой стороны, использование OJS предполагает дополнительную нагрузку на членов редакции: первоначальная регистрация рецензентов, при повторном к ним обращении они часто не могут зайти на сайт повторно, например, по причине потери логина и пароля. Также Юрий Иванович прокомментировал запросы на рецензирование и отказы дать рецензию. Обычно на 5 запросов приходится 1 отказ и 2-3 человека вообще не отвечают на запросы о рецензировании. В среднем на одну статью приходится 2-3 раунда рецензирования. Может быть отправлен повторный запрос на рецензирование, если нет откликов. Рецензии могут быть отправлены в Publons и eLibrary.ru. Стоимость подключения к Publons для издательства - 1,5 тыс. долларов в год.

Вполне очевидно, что российская сессия в рамках недели рецензирования была тесно связана с проблемами, которые обсуждались на глобальном уровне. Подобный формат взаимодействия позволяет российским научным редакторам не просто ознакомиться с лучшими мировыми практиками, связанными с функционированием и развитием института рецензирования, но и вносить свой вклад в его эволюцию и формирование доверия к нему.

\section{СПИСОК ЛИТЕРАТУРЫ}

1. Meadows A. In Peer Review Week We Trust. Available at: https://scholarlykitchen.sspnet.org/2020/04/09/inpeer-review-week-we-trust//

2. Peer Review Week 2020. Available at: https://peerreviewweek.wordpress.com/peer-review-week-2020/

3. Wallace J. How to be a good Peer Reviewer. Available at: https://scholarlykitchen.sspnet.org/2019/09/17/howto-be-a-good-peer-reviewer/

4. Kupferschmidt K. 'A completely new culture of doing research'. Coronavirus outbreak changes how scientists communicate. Available at: https://www.sciencemag.org/news/2020/02/completely-new-culture-doing-researchcoronavirus-outbreak-changes-how-scientists

5. Black C., Kowalczuk M., Alam S., Moylan E., Jones L., Mehmani B., Stein G., Larkin A., van Rossum J. Peer

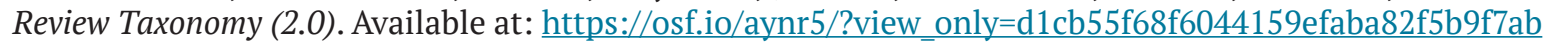

6. Meadows A., Wallace J., Wulf K. Trust as an Ethic and a Practice in Peer Review. Available at: https:// scholarlykitchen.sspnet.org/2020/09/21/trust-as-an-ethic-and-a-practice-in-peer-review/

7. Grinham L. R. Peer Review Week 2020 at Communications Biology. Available at: https://natureecoevocommunity. nature.com/posts/peer-review-week-2020-at-communications-biology

8. Allen L., O’Connell A., Kiermer V. How can we ensure visibility and diversity in research contributions? How the Contributor Role Taxonomy (CRediT) is helping the shift from authorship to contributorship. Learned Publishing. 2019;32(1):71-74. DOI: 10.1002/leap.1210.

Материал подготовила Е. В. Тихонова

Для цитирования: Тихонова Е. В. Международный форум «Peer Review Week 2020», 21-25 сентября 2020 г. Сессия Российского отделения Европейской ассоциации научных редакторов (EASE) и Acсоциации научных редакторов и издателей (АНРИ), 24 сентября 2020 г., Москва, Россия. Научный редактор и издатель. 2020;5(2):135-144. DOI: 10.24069/2542-0267-2020-2-135-144.

For citation: Tikhonova E. V. Peer Review Week 2020, September 21-25, 2020: Joint Session of the Russian Regional Chapter of EASE \& Association of Science Editors and Publishers (ASEP), September 24, 2020, Moscow, Russia. Nauchnyi redaktor i izdatel' = Science Editor and Publisher. 2020;5(2):135-144. DOI: 10.24069/25420267-2020-2-135-144. 